\title{
Computing Techniques for Modeling the Retention of Polar Pharmaceutical Active Compounds by Membranes
}

Yamina Ammi ( $\square$ ammi.yamina@yahoo.fr)

Universite Dr Yahia Fares de Medea https://orcid.org/0000-0003-2599-5828

Cherif Si Moussa

Universite Dr Yahia Fares de Medea

Salah Hanini

Universite Dr Yahia Fares de Medea

\section{Research Article}

Keywords: Computing Techniques, Modeling, Retention, Polar Pharmaceutical Active Compounds, Membranes

Posted Date: February 21st, 2022

DOI: https://doi.org/10.21203/rs.3.rs-1120285/v1

License: (c) (i) This work is licensed under a Creative Commons Attribution 4.0 International License. Read Full License 


\title{
Computing Techniques for Modeling the Retention of Polar Pharmaceutical Active Compounds by Membranes
}

\author{
Yamina Ammi ${ }^{1 *}$, Cherif Si- Moussa ${ }^{1}$, Salah Hanini ${ }^{1}$ \\ ${ }^{1}$ Laboratory of Biomaterials and Transport Phenomena (LBMPT), University of Médéa, \\ 26000, Algeria. \\ *Corresponding author: Email: ammi.yamina@yahoo.fr \\ Phone number: +2130793015912
}




\begin{abstract}
The retention of polar pharmaceutical active compounds (PPhACs) by nanofiltration (NF) and reverse osmosis (RO) membranes is of paramount importance in membrane separation processes. The retention of $21 \mathrm{PPhACs}$ was correlated using computational intelligence techniques (feedforward neural networks multi-layer perceptron, feedforward neural networks radial basis function, and support vector machines). A database of 541 retention values has been collected from the literature. The results showed a high training and predictive capacity of the FNN-MLP model for the retention of PPhACs by NF/RO with a very high correlation coefficient $(\mathrm{R}=0.9714)$ and a very low root mean squared error $(\mathrm{RMSE}=3.9139 \%)$ for the all phase, which the FNN-MLP model is better than that obtained using FNN-RBF model $(\mathrm{R}=0.7807$ and $\mathrm{RMSE}=10.2785 \%)$ and SVM model $(\mathrm{R}=0.9677$ and $\mathrm{RMSE}=4.1598)$. The sensitivity analysis was computed and emphasized that the retention of PPhACs is governed by three interactions arranged in descending order: the polarity interactions (hydrophobicity/hydrophilicity) (Relative Importance RI = $75.68 \%)$, electrostatic repulsion $(\mathrm{RI}=58.88 \%)$, and steric hindrance $(\mathrm{RI}=54.73 \%$ and $\mathrm{RI}=$ $32.25 \%$ ). This research suggests that the PPhACs retention on the NF/RO strongly depend much more on the topological polar surface area.
\end{abstract}

Keywords: Computing Techniques; Modeling; Retention; Polar Pharmaceutical Active Compounds; Membranes. 


\section{Introduction}

The presence of organic compounds in natural water sources is regarded as a high-priority environmental issue. In particular, Polar pharmaceuticals active compounds (PPhACs) can be highly water mobile, potentially reaching source waters and even finished drinking water. Polar pharmaceuticals active compounds (PPhACs) are highly polar chemicals and tend to accumulate due to their low degradation properties and slow adsorption kinetics in water cycles (Albergamo et al. 2019; Teychene et al. 2020).

Pharmaceuticals active compounds (PhACs) are eliminated by superior technologies. Membrane processes such as reverse osmosis (RO) and nanofiltration (NF) are excellent technological solutions to eliminate PhACs, and protect human beings and the environment. Really, several studies have already demonstrated that NF/RO processes can eliminate pharmaceutical's active compounds (PhACs). Globally, studies relate retention efficiency with complex solute-membrane interactions (steric hindrance, electrostatic repulsion, and hydrophobic-adsorption interactions). Solute-membrane interactions are in turn influenced by compound characteristics (such as molecular size, polarity, charge, and hydrophobicity), membrane properties (porosity, polarity, and electrostatic charges), and operating filtration conditions $(\mathrm{pH}$, pressure, permeate flux, temperature, membrane fouling, recovery, and cross-flow velocity) (Teychene et al. 2020; Kim et al. 2018).

Modeling the retention of organic compounds by NF/RO membranes is a very tool important for developing robust high-pressure membrane technologies. However, there have been fewer models to "predict" the retention of organic compounds for reasons of the complexity of this mechanistic (Libotean et al. 2008; Yangali-Quintanilla et al. 2008; 2009; 2010; Arash et al. 2013; Ammi et al. 2015; Flyborg et al 2017; Khaouane et al. 2017; Ammi et al. 2018; 2020; 2021a; 2021b; Nohyeong et al. 2021). These research works have been conducted to investigate the use of multiple linear regressions (MLR), artificial neural networks (ANN), bootstrap aggregated neural networks (BANN), partial least squares (PLS), and support vector machines (SVM) models based on quantitative structure-activity relationship (QSAR) to correlate, model, and predict the retention of organic compounds (neutral and ionic) by NF/RO membranes including (pharmaceuticals, endocrine disrupting compounds, pesticides, alcohols, phenols, and solvents). Whereas, there is no modeling study for the retention of organic compounds by NF/RO membranes using feedforward neural networks radial basis function (FNN-RBF). 
In this present study, an attempt will be made to estimate the retention of the polar pharmaceutical active compounds (PPhACs) by nanofiltration and reverse osmosis membranes using three an artificial intelligence approach (feedforward neural networks multi-layer perceptron, feedforward neural networks radial basis function, and support vector machine). A similar set of inputs is considered for the three approaches that include an effective diameter of the organic compound in water " $\mathrm{d}_{\mathrm{c}}$ ", $\log \mathrm{D}_{\mathrm{ow}}$, dipole moment, molecular length, molecular equivalent width, molecular weight cut-off, sodium chloride salt rejection, zeta potential, contact angle, $p H$, pressure, temperature, and recovery.

To the best of our knowledge, this will be the first attempt to model the polar pharmaceutical active compounds (PPhACs) retention mechanisms by nanofiltration and reverse osmosis (NF/RO) membranes using three an artificial intelligence approach (feedforward neural networks multilayer perceptron "FNN-MLP", feedforward neural networks radial basis function "FNN-RBF", and support vector machine "SVM").

Therefore, The present work aims at modeling the polar pharmaceutical active compounds (PPhACs) retention mechanisms by nanofiltration and reverse osmosis membranes. The remainder of this study is structured as follows: Section 2 includes retention prediction of $\mathrm{PPhACs}$ using hybrid learning architecture. Section 3 describes modeling details. Resultants and discussion, analyse and comparison of prediction models are presented in Sections 4 and 5, respectively. We will end with a conclusion that brings together the main results obtained in Section 6.

\section{Retention Prediction of PPhACs Using Hybrid Learning Architecture}

\subsection{Feedforward Neural Networks (FNN)}

The feedforward neural networks (FNN) is therefore presented graphically by a set of neurons connected. Information flowing from the inputs to the outputs without (backbox). We can see that the graph of feedforward neural networks is acyclic. Indeed, if we move in this type of network from any neuron by following the connections, we cannot go back to the starting neuron. The neurons that perform the final computation of the composition of functions are the output neurons. Those who perform intermediate calculations are the hidden neurons. The Feedforward neural networks are structured such that neurons that belong to the same layer are not connected, each of the layers receiving signals from the previous layer and transmitting the result of its processing to the next layer. The two extreme layers correspond to the input layer which receives its inputs from 
the outside environment on the one hand and to the output layer which provides the result of the treatments carried out on the other hand. The intermediate layers are called hidden layers, their number is variable (Ammi et al. 2020; Khaouane et al. 2013; Meshram et al. 2020). The feedforward neural networks can be given as follow for the prediction of the polar pharmaceutical active compounds (PPhACs) retention mechanisms by nanofiltration and reverse osmosis membranes (Fig 1).

With:

$\mathrm{i}(\mathrm{i}=1: \mathrm{n}=13)$ is the number of neurons in the input layer, $j(\mathrm{j}=1: \mathrm{m})$ is the number of neurons in the output layer, $\mathrm{k}(\mathrm{k}=1)$ is the number of neurons in the output layer, $x_{i}$ is the inputs of the FNN,

$w_{i}^{I}$ is the weights of the input layer, $w_{j}^{H}$ is the weights of the hidden layer, $b_{j}^{H}$ is the bias of the hidden layer, $b_{1}^{O}$ is the bias of the output layer, $f_{H}$ is the transfer function in the hidden layer, and $f_{O}$ is the transfer function in the output layer.

The feedforward neural networks multi-layer perceptron (FNN-MLP) and the radial basis function (FNN-RBF) are the networks most used in the literature. In what follows, we will illustrate each of them.

The feedforward neural networks' multi-layer perceptron (FNN-MLP) is an extension of the previous one, with one or more layers hidden between the inputs and the outputs. Each neuron in the layer is associated with all neurons in the previous layer and the next layer. It can solve nonlinearly separable problems and complicated logic problems (Talbi et al. 2011). It follows supervised training (Meshram et al. 2020). This FNN-MLP was chosen for the rest of our research work.

The feedforward neural networks Radial Basis Function (FNN-RBF) or more simply radial base networks have been proposed by Moody and Darken. The RBF is the feedforward neural network as a multi-layer perceptron. The feedforward neural networks RBF will therefore be used in the same types of problems as a multi-layer perceptron, namely, in the classification and approximation of functions, particularly. The most learning used for RBF is a hybrid model (Talbi et al. 2011).

\subsection{Support Vector Machine (SVM)}

Similar to NN, the primary concept underlying SVM is that neurons are organized in two layers (Fig 2). However, unlike feedforward neural networks, these approaches are based on statistical 
learning theory (SLT) implements structural risk minimization (SRM) theory and different error optimization techniques (Ammi at al. 2021a; Benimam et al.2020).

The nonlinear relationship between inputs and outputs in the support vector machine model can be employed by the regression function. The outputs of the SVM model are obtained by the following equation (García-Alba et al. 2019):

$f\left(x_{i}\right)=\omega^{T} \emptyset\left(x_{i}\right)+b, i=1,2, \ldots, n$

$\mathrm{f}\left(\mathrm{x}_{\mathrm{i}}\right)$ : the predicted value of the SVM model;

$\emptyset\left(\mathrm{x}_{\mathrm{i}}\right)$ : the nonlinear function that maps input finite-dimensional space into a higher-dimensional space which is implicitly created;

$\omega$ : the weight vector of the SVM model to be optimized;

b: the bias of the SVM model to be optimized.

The database has a D-dimensional input vector $\mathrm{x}_{\mathrm{i}} \in \mathrm{R}^{\mathrm{D}}$ and a scalar output $\mathrm{y}_{\mathrm{i}} \in \mathrm{R}$.

The SVM optimization model is given by the following equations (for the training database):

$$
\left\{\begin{array}{c}
\min \mathrm{R}\left(\mathrm{w}, \xi, \xi^{*}, \varepsilon\right)=\frac{1}{2}\|\mathrm{w}\|^{2}+\mathrm{C}\left[\mathrm{v} \varepsilon+\frac{1}{\mathrm{~N}} \sum_{\mathrm{i}=1}^{\mathrm{N}}\left(\xi_{\mathrm{i}}+\xi_{\mathrm{i}}^{*}\right)\right] \\
\text { subjective to }: \mathrm{y}_{\mathrm{i}}-\mathrm{w}^{\mathrm{T}} \varphi\left(\mathrm{x}_{\mathrm{i}}\right)-\mathrm{b} \leq \varepsilon+\xi_{\mathrm{i}} \\
\mathrm{w}^{\mathrm{T}} \varphi\left(\mathrm{x}_{\mathrm{i}}\right)+\mathrm{b}-\mathrm{y}_{\mathrm{i}} \leq \varepsilon+\xi_{\mathrm{i}} \\
\xi^{*}, \varepsilon \geq 0
\end{array}\right.
$$

C: the parameter used to balance the empirical risk and model complexity term $\|\mathrm{w}\|^{2}$ $\xi_{\mathrm{i}}^{*}$ : the slack variable to denote the distance of the ith sample outside of the $\varepsilon$-tube As a standard nonlinear constrained optimization problem, the above problem, the above problem can be resolved by constructing the dual optimization problem based on the Lagrange multipliers techniques:

$$
\left\{\begin{array}{c}
\max R\left(a_{i}, a_{i}^{*}\right)=\sum_{i=1}^{N} y_{i}\left(a_{i}, a_{i}^{*}\right)-\frac{1}{2} \sum_{i=1}^{N} \sum_{j=1}^{N}\left(a_{i}, a_{i}^{*}\right)\left(a_{j}, a_{j}^{*}\right) K\left(x_{i}, x_{j}\right) \\
\text { subjective to }: \sum_{i=1}^{N} y_{i}\left(a_{i}, a_{i}^{*}\right)=0 \\
0 \leq a_{i}, a_{i}^{*} \leq C / N \\
\sum_{i=1}^{N}\left(a_{i}+a_{i}^{*}\right) \leq \text { C. } v
\end{array}\right.
$$

$\mathrm{K}\left(\mathrm{x}_{\mathrm{i}}, \mathrm{x}_{\mathrm{j}}\right)$ : the kernel function satisfying the Mercer's condition;

$\mathrm{a}_{\mathrm{i}}$ and $\mathrm{a}_{\mathrm{i}}^{*}$ : the nonnegative Lagrange multipliers, respectively.

$\hat{y}=f\left(x_{i}\right)=\sum_{i=1}^{N}\left(a_{i}-a_{i}^{*}\right) K\left(x-x_{i}\right)+b, i=1,2, \ldots, n$ 


\subsection{Data experimental of polar pharmaceutical active compounds}

Scientific literature (Yangali-Quintanilla et al. 2008; 2009; Bellona et al. 2005; Long et al. 2007; Tang et al. 2009; Huang et al. 2011; Dolar et al. 2011; 2013a; 2013b; 2012; Jorge et al. 2017; Karla et al. 2018; Yang et al. 2018; Rui et al. 2019 ; Couto et al. 2020) data were reviewed to select 541 retentions based on 21 polar pharmaceutical active compounds (PPhACs). The PPhACs were assigned to three physicochemical properties categories based on their hydrophobicity (log $\mathrm{D}_{\mathrm{ow}}$ ), polarity (dipole moment), and size (effective diameter of PhACs in water " $\mathrm{d}_{\mathrm{c}}$ ", molecular length, and molecular equivalent width "eqwidth"). The retention mechanisms of PPhACs by nanofiltration and reverse osmosis membranes were based on the sieving effect, electrostatic interactions, and hydrophobic/adsorption interactions between solutes and NF/RO membranes. These solute-membrane interactions are determined by PPhACs properties, membrane characteristics (molecular weight cut-off "MWCO", sodium chloride salt rejection "SR ( $\mathrm{NaCl}$ )", surface membrane charge "zeta potential" and membrane hydrophobicity "contact angle"), and filtration conditions ( $\mathrm{pH}$, pressure, temperature, and recovery). The first step in constructing a prediction model, such as FNN-MLP, FNN-RBF, and SVM, is the determination of input variables or factors. The input and output variables considered in this study and statistical analysis are mentioned in table 1 . The statistical analysis of the inputs and output data was done in terms of the domain studied and their standard deviation "SD" for the database total.

\section{Modeling Details}

\subsection{Model Development}

Three models, FNN-MLP, FNN-RBF, and SVM were implemented and assessed in retention prediction of polar pharmaceutical active compounds ( $\mathrm{PPhACs)}$ by NF/RO membranes. Fig 3 is shown the procedure of the development and optimization of the architecture of FNN-MLP, FNNRBF, and SVM. For the total database, the three models (FNN-MLP, FNN-RBF, and SVM) were developed. The samples were subdivided into two subsets (training phase and testing phase).

To create the optimal feedforward neural networks multi-layer (FNN-MLP) models, we used the BFGS quasi-Newton (trainbfg) as training algorithm, four activation functions in the hidden layer (the tangent sigmoid (tansig), the log sigmoid (logsig), sin, and the exponential), and one activation function in the output layer (purelin). We varied the number of hidden neurons (minimum 03 neurons and maximum 25 neurons) till the best model was obtained. The trial-and-error method 
was performed to obtain the optimal feedforward neural networks multi-layer (FNN-MLP) models.

In order to build the feedforward radial basis function (FNN-RBF) model, the "Gaussian radial basis function" and "linear" activation function were appointed for the hidden and output layer, respectively. We varied the number of hidden neurons (minimum 03 neurons and maximum 25 neurons) till the best model was obtained.

To develop an optimal SVM model, the support vector machine learning technique is employed. As mentioned previously in this article, the choice of the kernel functions is crucial for model performance. STATISTICA SVM supports several kernel functions for use in support vector machine models. The penalty term of the parameters of the Gaussian radial basis function, $\mathrm{C}=$ 10.0000, $\mathrm{nu}=0.5000$, and Gamma $=3.51$, were determined for the SVM model and the optimal values of the target parameters were chosen.

The creation of feedforward neural networks (FNN-MLP and FNN-RBF) and support vector machine (SVM) models of the retention of polar pharmaceutical compounds active (PhACs) by nanofiltration and reverse osmosis membranes was performed using the STATISTICA software.

\subsection{Evaluation Criteria}

In this paper, thirteen error measures were utilized to assess the quality of prediction models: the Correlation Coefficient (R), the Mean Absolute Error (MAE), the Model Predictive Error (MPE), the Root Mean Squared Error (RMSE), the Standard Error of Prediction (SEP), Range Error Ratio (RER), Residual Predictive Deviation (RPD), the Mean Square Error (MSE), the Mean Relative Squared Error (MRSE), the Relative Absolute Error (RAE), the Accuracy factor $\left(\mathrm{A}_{\mathrm{f}}\right)$, Bias factor $\left(B_{f}\right)$, Relative Absolute Error (RAE), and Nash-Sutcliffe Efficiency (NSE) (Ammi et al. 2020; Meshram et al. 2020).

$$
\begin{aligned}
& \text { MAE }=\frac{1}{N} \sum_{i=1}^{N}\left|\left(y_{i, e x p}-y_{i, c a l}\right)\right| \\
& \operatorname{MPE}(\%)=\frac{100}{N} \sum_{i=1}^{n}\left|\frac{\left(y_{i, e x p}-y_{i, c a l}\right.}{y_{i, e x p}}\right| \\
& \operatorname{RMSE}=\sqrt{\frac{\sum_{i=1}^{N}\left(Y_{i, c a l}-Y_{i, e x p}\right)^{2}}{N}} \\
& \operatorname{SEP}(\%)=\frac{\text { RMSE }}{Y_{e}} \times 100 \\
& \operatorname{RER}=\frac{\text { Max-Min }}{\text { RMSE }}
\end{aligned}
$$




$$
\begin{aligned}
& \mathrm{RPD}=\frac{\mathrm{SD}}{\mathrm{RMSE}} \\
& \operatorname{MSE}=\frac{1}{\mathrm{~N}} \sum_{\mathrm{i}=1}^{\mathrm{N}}\left(\mathrm{y}_{\mathrm{i}, \exp }-\mathrm{y}_{\mathrm{i}, \mathrm{cal}}\right)^{2} \\
& \operatorname{MRSE}=\frac{1}{\mathrm{~N}} \sum_{\mathrm{i}=1}^{\mathrm{N}}\left(\frac{\mathrm{y}_{\mathrm{i}, \exp }-\mathrm{y}_{\mathrm{i}, \mathrm{cal}}}{\mathrm{y}_{\mathrm{i}, \exp }}\right)^{2} \\
& \mathrm{REA}=\sum_{\mathrm{i}=1}^{\mathrm{N}}\left|\frac{\mathrm{y}_{\mathrm{i}, \exp }-\mathrm{y}_{\mathrm{i}, \mathrm{cal}}}{\mathrm{y}_{\mathrm{i}, \exp }}\right| \\
& \left.A_{f}=10^{\left(\sum_{i=1}^{N}\left|\log \frac{y_{i, c a l}}{y_{i, e x p}}\right| / N\right.}\right) \\
& \left.\mathrm{B}_{\mathrm{f}}=10^{\left(\sum_{\mathrm{i}=1}^{\mathrm{N}} \log \frac{\mathrm{y}_{\mathrm{i}, \mathrm{cal}}}{\mathrm{y}_{\mathrm{i}, \exp }} / \mathrm{N}\right.}\right) \\
& \mathrm{RAE}=\frac{\sum_{\mathrm{i}=1}^{\mathrm{N}}\left|\mathrm{y}_{\mathrm{i}, \mathrm{cal}}-\mathrm{y}_{\mathrm{i}, \mathrm{exp}}\right|}{\sum_{\mathrm{i}=1}^{\mathrm{N}}\left|\overline{\mathrm{y}}_{\mathrm{i}, \mathrm{exp}}-\mathrm{y}_{\mathrm{i}, \exp }\right|} \\
& \mathrm{NSE}=\left|1-\left[\frac{\sum_{\mathrm{i}=1}^{\mathrm{N}}\left(\mathrm{Y}_{\mathrm{i}, \exp }-\mathrm{Y}_{\mathrm{i}, \mathrm{cal}}\right)^{2}}{\sum_{\mathrm{i}=1}^{\mathrm{N}}\left(\mathrm{Y}_{\mathrm{i}, \exp }-\overline{\mathrm{Y}}_{\mathrm{i}, \exp }\right)^{2}}\right]\right|, \infty \leq \mathrm{NSE} \leq 1
\end{aligned}
$$

We adopted the five-level interpretations of Residual Predictive Deviation "RPD" and Range Error Ratio "RER" provided by Viscarra Rossel: excellent predictions (RER and RPD > 2.5); good (RER and RPD of 2.0 to 2.5); approximate quantitative predictions (RER and RPD of 1.8 to 2.0); possibility to distinguish high and low values (RER and RPD of 1.4 to 1.8); and unsuccessful (RER and RPD < 1.40) (Ammi et al. 2020; Rossel et al. 2006).

Where $\mathrm{n}$ is the total quantity of data; $\mathrm{Y}_{\mathrm{i}, \exp }$ and $\mathrm{Y}_{\mathrm{i}, \mathrm{cal}}$ are the exp and calculated data of retention of PPhACs, respectively; and $\overline{Y_{1, e x p}}$ is the mean experimental data. SD is the standard deviation of experimental data, Min is the minimum of experimental data, and Max is the maximum of experimental data.

\section{Results and discussion}

The two most prevalent feedforward neural network designs, multi-layer perceptron (FNN-MLP) and radial basis function (FNN-RBF) were used for the retention of polar pharmaceutical compounds active (PhACs) by nanofiltration and reverse osmosis membranes. In the current work, nine models (three FNN-MLP, three FNN-RBF, and three SVM) having similar inputs were calibrated and evaluated.

Fig 4 illustrates the error values in term coefficient of correlation "R" obtained for the retention of polar pharmaceutical active compounds ( $\mathrm{PPACs}$ ) under the influence of the division of the 
database for feedforward neural networks (FNN-MLP and FNN-RBF) and support vector machine (SVM) model with division 1 (325 data for training phase (60\%), and 216 data for testing phase (40\%)), division 2 (379 data for training phase (70\%), and 162 data for testing phase (30\%)), and division 3 (433 data for training phase (80\%), and 108 data for testing phase (20\%)). The coefficients of correlations of division 3 are generally considered to be more excellent than the other divisions 1 and 2 for database total $(\mathrm{R}=0.9714$ for FNN-MLP, $\mathrm{R}=0.7807$ for FNN-RBF, and $\mathrm{R}=0.9677$ for $\mathrm{SVM}$ ). Therefore, it is clear that the third division represents the best result for modeling the retention of polar pharmaceutical active compounds (PPhACs) by nanofiltration and reverse osmosis membranes using the feedforward neural networks models (FNN-MLP and FNN-RBF) and support vector machine (SVM).

Hence, the structures of the feedforward neural networks multi-layer (FNN-MLP) models for the modeling of the retention of polar pharmaceutical active compounds (PPhACs) by nanofiltration and reverse osmosis membranes are more detailed architecture is illustrated in table 2 . The weight and bias matrices of the feedforward neural networks (FNN-MLP1, FNN-MLP2, and FNN-MLP3) models are depicted in supplementary data A (Table A.1, Table A.2, and Table A.3).

$\mathrm{W}_{\mathrm{I}}$ : the input-hidden layer connection weight matrix (15 rows x 13 columns);

$\mathrm{w}_{\mathrm{h}}$ : the hidden layer output connection weight matrix (15 rows $\mathrm{f} x 1$ column);

$\mathrm{b}_{\mathrm{h}}:$ the hidden neurons bias column vector (15 rows);

$b_{\mathrm{o}}$ : the output neurons bias column vector (1 row).

The retention of polar pharmaceutical active compounds (PPhACs) by nanofiltration and reverse osmosis membranes can be depicted by a mathematical (FNN-MLP) model incorporating all inputs $E_{i}$, it is given by the equations following:

The instance outputs $\mathrm{Z}_{\mathrm{j}}$ of the hidden layer:

$$
\begin{aligned}
& \mathrm{Z}_{\mathrm{j}(\mathrm{FNN}-\mathrm{MLP1})}=\mathrm{f}_{\mathrm{H}}\left[\sum_{\mathrm{i}=1}^{13} \mathrm{w}_{\mathrm{ji}}^{\mathrm{I}} \mathrm{E}_{\mathrm{i}}+\mathrm{b}_{\mathrm{j}}^{\mathrm{H}}\right]=\frac{\exp \left(\sum_{\mathrm{i}=1}^{13} \mathrm{w}_{\mathrm{ji}}^{\mathrm{I}} \mathrm{E}_{\mathrm{i}}+\mathrm{b}_{\mathrm{j}}^{\mathrm{H}}\right)-\exp \left(-\sum_{\mathrm{i}=1}^{13} \mathrm{w}_{\mathrm{ji}}^{\mathrm{I}} \mathrm{E}_{\mathrm{i}}+\mathrm{b}_{\mathrm{j}}^{\mathrm{H}}\right)}{\exp \left(\sum_{\mathrm{i}=1}^{13} \mathrm{w}_{\mathrm{ji}}^{\mathrm{I}} \mathrm{E}_{\mathrm{i}}+\mathrm{b}_{\mathrm{j}}^{\mathrm{H}}\right)+\exp \left(-\sum_{\mathrm{i}=1}^{13} \mathrm{w}_{\mathrm{ji}}^{\mathrm{I}} \mathrm{E}_{\mathrm{i}}+\mathrm{b}_{\mathrm{j}}^{\mathrm{H}}\right)} ; \mathrm{j}=1,2, \ldots, 9 \\
& \mathrm{Z}_{\mathrm{j}(\mathrm{FNN}-\mathrm{MLP2})}=\mathrm{f}_{\mathrm{H}}\left[\sum_{\mathrm{i}=1}^{13} \mathrm{w}_{\mathrm{ji}}^{\mathrm{I}} \mathrm{E}_{\mathrm{i}}+\mathrm{b}_{\mathrm{j}}^{\mathrm{H}}\right]=\frac{\exp \left(\sum_{\mathrm{i}=1}^{13} \mathrm{w}_{\mathrm{ji}}^{\mathrm{I}} \mathrm{E}_{\mathrm{i}}+\mathrm{b}_{\mathrm{j}}^{\mathrm{H}}\right)-\exp \left(-\sum_{\mathrm{i}=1}^{13} \mathrm{w}_{\mathrm{ji}}^{\mathrm{I}} \mathrm{E}_{\mathrm{i}}+\mathrm{b}_{\mathrm{j}}^{\mathrm{H}}\right)}{\exp \left(\sum_{\mathrm{i}=1}^{13} \mathrm{w}_{\mathrm{ji}}^{\mathrm{I}} \mathrm{E}_{\mathrm{i}}+\mathrm{b}_{\mathrm{j}}^{\mathrm{H}}\right)+\exp \left(-\sum_{\mathrm{i}=1}^{13} \mathrm{w}_{\mathrm{ji}}^{\mathrm{I}} \mathrm{E}_{\mathrm{i}}+\mathrm{b}_{\mathrm{j}}^{\mathrm{H}}\right)} ; \mathrm{j}=1,2, \ldots, 10 \\
& \mathrm{Z}_{\mathrm{j} \text { (FNN-MLP3) }}=\mathrm{f}_{\mathrm{H}}\left[\sum_{\mathrm{i}=1}^{13} \mathrm{w}_{\mathrm{ji}}^{\mathrm{I}} \mathrm{E}_{\mathrm{i}}+\mathrm{b}_{\mathrm{j}}^{\mathrm{H}}\right]=\frac{1}{1+\exp \left(-\sum_{\mathrm{i}=1}^{13} \mathrm{w}_{\mathrm{ji}}^{\mathrm{I}} \mathrm{E}_{\mathrm{i}}+\mathrm{b}_{\mathrm{j}}^{\mathrm{H}}\right)} ; \mathrm{j}=1,2, \ldots, 15
\end{aligned}
$$

The output "Retention of PPhACs"

Retention of PPhACs $(F N N-M L P)=f_{0}\left[\sum_{j=1}^{m} w_{1 j}^{H} Z_{j}+b_{1}^{o}\right]=\sum_{j=1}^{m} w_{1 j}^{H} Z_{j}+b_{1}^{o}$ 
The combination of the equations. (18), (19), (20) and (21) leads to the following mathematical formula, which describes the retention of polar pharmaceutical active compounds (PPhACs) assimilation by taking into account all inputs.

Retetion of PPhACs $(F N N-M L P 1)=\sum_{j=1}^{9} w_{1 j}^{H} \frac{\exp \left(\sum_{i=1}^{13} w_{j i}^{I} E_{i}+b_{j}^{H}\right)-\exp \left(-\sum_{i=1}^{13} w_{j i}^{I} E_{i}+b_{j}^{H}\right)}{\exp \left(\sum_{i=1}^{13} w_{j i}^{I} E_{i}+b_{j}^{H}\right)+\exp \left(-\sum_{i=1}^{13} w_{j i}^{I} E_{i}+b_{j}^{H}\right)}+b_{1}^{o}$

Retetion of PPhACs $(F N N-M L P 2)=\sum_{j=1}^{10} w_{1 j}^{H} \frac{\exp \left(\sum_{i=1}^{13} w_{j i}^{I} E_{i}+b_{j}^{H}\right)-\exp \left(-\sum_{i=1}^{13} w_{j i}^{I} E_{i}+b_{j}^{H}\right)}{\exp \left(\sum_{i=1}^{13} w_{j i}^{I} E_{i}+b_{j}^{H}\right)+\exp \left(-\sum_{i=1}^{13} w_{j i}^{I} E_{i}+b_{j}^{H}\right)}+b_{1}^{o}$

Retenion of PPhACs $(F N N-M L P 3)=\sum_{j=1}^{15} w_{1 j}^{H} \frac{1}{1+\exp \left(-\sum_{i=1}^{13} w_{j i}^{\mathrm{I}} E_{i}+b_{j}^{H}\right)}+b_{1}^{o}$

Table 3 displays the results of FNN-RBF models comprising various numbers of hidden neurons. In the training, test, and all phase of the FNN-RBF3 model, having 15 hidden nodes gave the best R, MAE, and RMSE $(0.7901,7.0832$, and 0.1025 for the training phase and $0.7448,8.2519$, and 10.9558 for the testing phase, $0.7807,7.3165$, and 10.2785 for all phase, respectively). According to the performance statistics in the test phase and all phase, the FNN-RBF3 (13-15-1) model was chosen as the best feedforward neural networks radial basis function (FNN-RBF) model for predicting the retention of polar pharmaceutical active compounds ( $\mathrm{PPACs}$ ) by nanofiltration and reverse osmosis membranes.

Table 4 sums up the accuracy of the support vector machine (SVM) for the training, the testing, and all phase. It is observed that in the total phase, SVM3 had the lowest MAE and RMSE, and the highest R (2.9686, 4.1598, and 0.9677, respectively). Nevertheless, SVM1 got the highest MAE and RMSE and lowest R (3.3278, 6.6650, and 0.9160, respectively) in the total phase.

The contribution of the input variables (dc, $\log \mathrm{D}_{\mathrm{ow}}$, length, Eqwidth, MWCO, $\mathrm{SR}(\mathrm{NaCl})$, contact angle, Zeta potential, $\mathrm{pH}$, pressure, recovery, and temperature) on the output (retention of PPhACs) was determined by a sensitivity analysis for FNN-MLP3 model. The relative importance (RI) and the contribution results are shown in fig 5. The most important variables that may influence the retention of polar pharmaceutical active compounds (PPhACs) by nanofiltration and reverse osmosis membranes are contact angle, Zeta potential, $\mathrm{SR}(\mathrm{NaCl}), \mathrm{MWCO}$, dc, pressure, recovery, Temperature, dipole moment, length, $\log \mathrm{D}_{\mathrm{ow}}$,eqwidth, $\mathrm{pH}$. All input relevant variables have a significant contribution ( $\mathrm{RI}>2$ ) to the retention of PPhACs. This sensitivity analysis successfully identified the true importance of all the variables used for the modeling of the retention of polar pharmaceutical active compounds (PPhACs) by nanofiltration and reverse osmosis membranes, and therefore, proves the correctness of the choice of variables that were used in this study. Figure 
5 shows that the membrane polarity interactions (hydrophobicity/hydrophilicity) "contact angle" in was even more important than surface membrane charge "zeta potential", steric hindrance "SR( $\mathrm{NaCl})$, and MWCO" with relative importance $\mathrm{RI}=75.68 \%, 58.88 \%, 54.73 \%$, and $32.25 \%$, respectively. These results confirm that the retention of polar pharmaceutical active compounds (PPhACs) by nanofiltration and reverse osmosis membranes depends on three interactions arranged in descending order (polarity interactions (hydrophobicity/hydrophilicity), electrostatic repulsion (charge effect), and steric hindrance (sieving effect)). This research work suggests that the polar pharmaceutical active compounds ( $\mathrm{PPhACs}$ ) retention on the NF/RO membranes strongly depends much more on the topological polar surface area.

In order to assess the predictive ability of the feedforward networks models (FNN-MLP3, FFNRBF3, and SVM3), the total agreement vector and the total agreement plot of the predicted versus experimental dependent variable from the total phases only are analyzed. Using the Matlab function "postreg", the plot of the predicted versus experimental, the total phases, and the parameters of the linear regression are directly obtained.

Fig 6 shows the predicted retention of PPhACs by NF/RO vs experimental retention of PPhACs by NF/RO agreement plot: a for the FFN-RBF, b for the SVM, and $\mathrm{c}$ for the FNN-MLP. The total phase for FNN-RBF model agreement scheme is shown in figure 6a which illustrates the FNNRBF model calculated outputs versus the experimental data with an agreement vector, [a(slope), $b$ (y intercept), R (correlation coefficient) $]=[0.6237,32.7976,0.7807]$, which implies acceptable FNN-RBF model robustness and the possibility of predicting the different parameters that characterize the retention of polar pharmaceutical active compounds by NF/RO membranes. The total phase for SVM model agreement scheme is mentioned in figure $6 \mathrm{~b}$ which illustrate the support vector machine model calculated outputs versus the experimental data with an agreement vector, [a(slope), b (y intercept), $\mathrm{R}$ (correlation coefficient)] $=[0.9158,7.2036,0.9677]$, which shows good robustness of the established SVM models and the possibility of predicting the different parameters that characterize the retention of PPhACs during NF/RO membrane. The figure $6 \mathrm{c}$ shows the total agreement plot which mentioned the predicted retention of PPhACs values following exactly the trend of the experimental retention of PPhACs values with an agreement vector approaching the ideal, [a (slope), $\mathrm{b}$ ( $\mathrm{y}$ intercept), $\mathrm{R}$ (correlation coefficient)] = $[0.9544,3.7142,0.9714]$, which demonstrates the predictive ability and accuracy of our model 
"FNN-MLP". This reveals the ideal modeling of the whole data by the optimized feedforward networks' multi-layer perception (FNN-MLP).

\section{Analyse and comparison of prediction models}

We investigated the ability of the FNN-MLP model for predicting the retention of polar pharmaceutical active compounds (PPhACs) by nanofiltration and reverse osmosis membranes and compared it with FNN-RBF and SVM models. The accuracies of the FNN-MLP, FNN-RBF, and SVM models were compared using the R, MAE, MPE, RMSE, SEP, RER, RPD, MSE, MRSE, RAE, $A_{f}, B_{f}$, RAE, and NSE. Table 5 presents the total phase results, it is shown that the FFNMLP model acquired the lowest errors of, MAE, MPE, RMSE, SEP, MSE, MRSE, RAE, $A_{f}, B_{f}$, and RAE, in the total phases $(2.4410,3.3318,3.9139,4.4784,15.3184,2.05 \mathrm{E}-05,0.0045,1.0060$, 1.0060, 0.1967 respectively) and the highest errors of the R, RER, RPD, and NSE (0.9714, 25.2205, 4.2043, and 1.15E+25, respectively), it can be seen that the FNN-MLP based model surpassed the FNN-RBF and SVM models. Results indicated that the FNN-MLP model might provide an alternative to the FNN-RBF and SVM models for predicting the retention of polar pharmaceutical active compounds (PPhACs) by nanofiltration and reverse osmosis membranes.

\section{Applicability domain}

In the present study, the Leverage mathematical technique was used to find outliers. In this technique, there the residual values and a Hat matrix are employed. The path detailed for creating the Hat values, and the main steps are the following (Hamadache et al. 2018):

$H=X\left(X^{t} X\right)^{-1} X^{t}$

where $\mathrm{X}$ refers to the $\mathrm{m} \times \mathrm{n}$ matrix ( $\mathrm{m}$ and $\mathrm{n}$ represent the number of samples and the parameters (input variables) of the model, respectively). The Hat values are obtained from the main diagonal of the $\mathrm{H}$ matrix.

Hat $=$ diagonal $(\mathrm{H})$

The William diagram which represents the residuals normalized against the "Leverage" lever (Hat) can graphically detect outliers. In this graph, the critical lever $(\mathrm{H} *)$ (threshold) is generally set at the value given by the following equation: 
$\mathrm{H}^{*}=\frac{3(\mathrm{n}+1)}{\mathrm{m}}=\frac{3(13+1)}{541}=0.0776$

The normalized residuals are calculated from the data of the retention experimental and that calculated by the model.

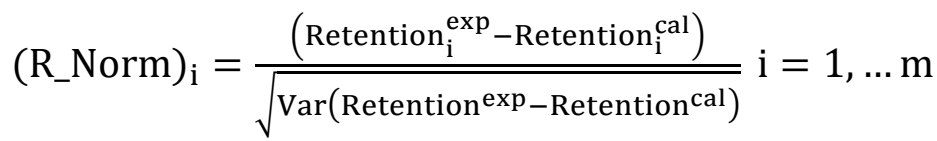

Normalized residuals equal to \pm 3 are considered margin limits for validated data, whereas residuals outside these ranges define suspected data. In addition, all data points with Hat values $>\mathrm{H}^{*}$ are also considered as suspected data. The results of the outlier analysis are mentioned in Fig 7. Based on the above-mentioned figure, the critical lever $\mathrm{H}^{*}$ value is 0.0776 , and only the data showed by red circles is the valid data and for which the model's accuracy is confirmed. The analysis of the outliers of the FNN-MLP3 model "trainbr, logsig" revealed the results represented on the William diagram of fig 7(a) where it is observed that 513/541 (94.82\%) points belong to the domain of validity and that only $28 / 541(5.17 \%)$ points are outside the domain of applicability of the optimized FNN-MLP3 model. Fig 7(b) shows William's diagram for the domain of applicability for the optimal FNN-RBF3 model. In this chart the existence of 518/541 (95.75\%) valid data points and 23/541 (4.25\%) suspicious data points. The analysis of the outliers of the model optimized by the SVM method using the Gaussian kernel function of STATISTICA revealed the results represented on the William diagram of fig7(c) where it is observed that 518/541 (95.75\%) points belong to the domain of validity and only $23 / 541(4.25 \%)$ points are outside the domain of applicability of the optimized SVM model.

\section{Conclusions}

In the present study, the prediction of the retention of polar pharmaceutical active compounds (PPhACs) by nanofiltration and reverse osmosis membranes using three feedforward networks multi-layer perceptron and feedforward networks radial basis function (FNN-MLP and FNN-RBF) with supervised learning, involving the "Quasi- Newton BFGS" algorithm. The BFGS quasiNewton training algorithm (trainbfg) gives better results in terms of speed, convergence, and generation of performance for the FNN-MLP model. The results showed a high training and predictive capacity for the retention of polar pharmaceutical active compounds ( $\mathrm{PPhACs}$ ) by nanofiltration and reverse osmosis membranes with a very high correlation coefficient $(\mathrm{R}=$ 
0.9714 ) and a very low root mean squared error (RMSE $=3.9139 \%$ ) for all phase. In addition, they showed a better choice of training algorithm, activation functions, and network architecture [1315-1] obtained by applying statistical indicators of robustness. The prediction by feedforward networks multi-layer perceptron (FNN-MLP) also shows a good correlation between the experimental and predicted values of the retention of polar pharmaceutical active compounds (PPhACs) by nanofiltration and reverse osmosis membranes, meaning that the FNN-MLP model has better predictive power. The sensitivity analysis was computed and emphasized that the retention of polar pharmaceutical active compounds (PPhACs) by nanofiltration and reverse osmosis membranes is governed by three interactions arranged in descending order: the polarity interactions (hydrophobicity/hydrophilicity) (Relative Importance RI $=75.68 \%$ ), electrostatic repulsion (charge effect) $(\mathrm{RI}=58.88 \%)$, and steric hindrance (sieving effect) $(\mathrm{RI}=54.73 \%$ and $\mathrm{RI}=32.25 \%$ ). This research work suggests that the polar pharmaceutical active compounds (PPhACs) retention on the NF/RO membranes strongly depends much more on the topological polar surface area.

Acknowledgments: The authors gratefully acknowledge the Ministry of Higher Education of Algeria (PRFU Projects $\mathrm{N}^{\circ}$ A16N01UN260120220004) and the group of Laboratory of Biomaterials and Transport Phenomena in university of Medea.

\section{Declarations}

Conflict of interest The authors at this moment declare that they have no conflict of interest, and any funding agency has not supported this work.

\section{References}

Albergamo V, Blankert B, Cornelissen E.R, Hofs B, Knibbe W-J, Van der Meer W, de Voogt P. (2019) Removal of polar organic micropollutants by pilot-scale reverse osmosis drinking water. treatment. Water Research 148: 535-545. https://doi.org/10.1016/j.watres.2018.09.029.

Ammi Y, Khaouane L, Hanini S (2015) Prediction of the rejection of organic compounds (neutral and ionic) by nanofiltration and reverse osmosis membranes using neural networks. Korean $\mathbf{J}$ Chem Eng, 32 (11):2300-2310. https://doi:10.1007/s11814-015-0086-y.

Ammi Y, Khaouane L, Hanini S (2018) A Model Based on Bootstrapped Neural Networks for Modeling the Removal of Organic Compounds by Nanofiltration and Reverse Osmosis 
Membranes. Arabian Journal for Science and Engineering 43 (11):6271-6284. https://doi:10.1007/s13369-018-3484-8.

Ammi Y, Khaouane L, Hanini S (2020) Comparison of "Neural Networks and Multiple Linear Regressions" Models to Describe the Rejection of Micropollutants by Membranes. Kemija u Industriji, 69 (3-4):111-127. https://doi.org/10.15255/KUI.2019.024.

Ammi Y, Hanini S, Khaouane L (2021a) An artificial intelligence approach for modeling the rejection of anti-inflammatory drugs by nanofiltration and reverse osmosis membranes using kernel support vector machine and neural networks. Comptes Rendus Chimie 24 : 243-254. https://doi.org/105802/crchim.76.

Ammi Y, Khaouane L, Hanini S (2021b) Stacked neural networks for predicting the membranes performance by treating the pharmaceutical active compounds. Neural Computing and Applications 19. https://doi.org/10.1007/s00521-021-05876-0.

Arash S, Christopher B (2013) Application of quantitative structure-property relationships (QSPRs) to predict the rejection of organic solutes by nanofiltration, Separation and Purification Technology 118 627-638. https://doi.org/10.1016/j.seppur.2013.07.050.

Bellona C, Drewes J.E. (2005) The role of membrane surface charge and solute physico-chemical properties in the rejection of organic acids by NF membranes. Journal of Membrane Science 249 (2-1): 227-234. http://dx.doi.org/10.1016/j.memsci.2004.09.041.

Benimam H, Si-Moussa C, Laidi M, Hanini S (2020) Modeling the activity coefficient at infinite dilution of water in ionic liquids using artificial neural networks and support vector machines. Neural Computing and Applications 32 : 8635-8653. https://doi.org/10.1007/s00521-019-04356w.

Couto C.F, Santos A.V, Amara C.S, Lange L.C, Andrade L.H, Foureaux A.F.S, Fernandes B.T (2020) Assessing potential of nanofiltration, reverse osmosis and membrane distillation drinking water treatment for pharmaceutically active compounds ( $\mathrm{PhACs}$ ) removal. Journal of Water Process Engineering 33:101029. https://doi.org/10.1016/j.jwpe.2019.101029.

Dolar D, Vuković A, Ašperger D, Košutić K (2011) Effect of water matrices on removal of veterinary pharmaceuticals by nanofiltration and reverse osmosis membranes. Journal of Environmental Sciences 23 (8):1299-1307. http://dx.doi.org/10.1016/S1001-0742(10)60545-1. 
Dolar D, Kosutic K, Asperger D (2013a) Influence of Adsorption of Pharmaceuticals onto RO/NF Membranes on Their Removal from Water. Water Air Soil Pollut Water, Air, \& Soil Pollution : An International Journal of Environmental Pollution 224 (1):1-13(2013a). http://dx.doi:10.1007/s11270-012-1377-0.

Dolar D, Košutić K, Periša, M, Babić S (2013b) Photolysis of enrofloxacin and removal of its photodegradation products from water by reverse osmosis and nanofiltration membranes.

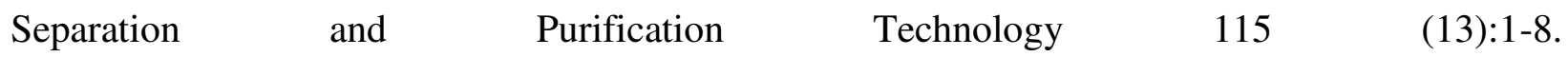
http://dx.doi.org/10.1016/j.seppur.2013.04.042.

Dolar, D. Ignjatic Zokic, T. Kosutic, K. Asperger, D. Mutavdzic, PD.: RO/NF membrane treatment of veterinary pharmaceutical wastewater: comparison of results obtained on a laboratory and a pilot scale. Environmental science and pollution research international 19 (4):1033-1042(2012). http://dx.doi.org/10.1007/s11356-012-0782-7.

Flyborg L, Björlenius B, Ullner M, Persson K.M (2017) A PLS model for predicting rejection of trace organic compounds by nanofiltration using treated wastewater as feed. Separation and Purification Technology 174 : 212-221. https://doi.org/10.1016/j.seppur.2016.10.029.

García-Alba J, Bárcena JF, Ugarteburu C, García A (2019) Artificial neural networks as emulators of process-based models to analyse bathing water quality in estuaries. Water Research $150: 283$ 295. https://doi.org/10.1016/j.watres.2018.11.063.

Hamadache M, Benkortbi O, Hanini S, Amrane A (2018) QSAR modeling in ecotoxicological risk assessment: application to the prediction of acute contact toxicity of pesticides on bees (Apis mellifera L). Environ Sci Pollut Res 25:896-907. https://doi.org/10.1007/s11356-017-0498-9.

Huang H, Cho H, Schwab K, Jacangelo JG (2011) Effects of feedwater pretreatment on the removal of organic microconstituents by a low fouling reverse osmosis membrane. Desalination 281 (0):446-454. http://dx.doi.org/10.1016/j.desal.2011.08.018.

Jorge GILM, Manuele M, Carlos CA, Maria-Isabel AM M II-C (2017) Nanofiltration as tertiary treatment method for removing trace pharmaceutically active compounds in wastewater from wastewater treatment plants. Water Research 15 (125):360-373. http://dx.doi.org/10.1016/j.watres.2017.08.070.

Karla LJVN, Natalia F(2018) Assessing potential of nanofiltration and reverse osmosis for removal of toxic pharmaceuticals from water. Journal of Water Process Engineering 25:195-204. http://dx.doi:10.1016/j.jwpe.2018.08.002. 
Kim S, Chu K.H, Al-Hamadani Y.A.J, Park C.M, Jang M, Kim D, Yu M, Heo J, Yoon Y (2018) Removal of contaminants of emerging concern by membranes in water and wastewater: a review. Chemical Engineering Journal 335 : 896-914. https://doi.org/10.1016/j.cej.2017.11.044.

Khaouane L, Ammi Y, Hanini S (2017) Modeling the Retention of Organic Compounds by Nanofiltration and Reverse Osmosis Membranes Using Bootstrap Aggregated Neural Networks. Arabian Journal for Science and Engineering 42 (4):1443-1453. https://doi:10.1007/s13369-0162320-2.

Khaouane L (2013). Etude et Modélisation de la Biosynthèse des Antibiotiques à partir de Différentes Souches Productrices - Cas de Pleuromutiline, Chemical Engineering, University of Médéa, Algeria.

Libotean D, Giralt J, Rallo R, Cohen Y, Giralt F, Ridgway HF (2008) Rodriguez, G. Phipps, D.: Organic compounds passage through RO membranes. Journal of Membrane Science 313 (1-2):2343. http://dx.doi.org/10.1016/j.memsci.2007.11.052.

Long S.H, Nghiem D (2007) Effects of membrane fouling on the nanofiltration of pharmaceutically active compounds (PhACs): Mechanisms and role of membrane pore size. $\begin{array}{llllll}\text { Separation } \quad \text { and } & \text { Purification } & \text { Technology } & 57 & \text { (1): }\end{array}$ http://dx.doi.org/10.1016/j.seppur.2007.04.002.

Meshram S.G, Singh V.P, Kisi O, Karimi V, Meshram C (2020) Application of Artificial Neural Networks, Support Vector Machine and Multiple Model-ANN to Sediment Yield Prediction. Water Resources Management 34 : 4561-4575. https://doi.org/10.1007/s11269-020-02672-8.

Nohyeong J, Tai-heng C, Tiezheng T (2021) Predicting micropollutant removal by reverse osmosis and nanofiltration membranes: Is machine learning viable? Environmental Science \& Technology 55: (16) 11348-11359. https://doi.org/10.1021/acs.est.1c04041.

Rossel RN, McGlynn A.B, McBratney R.A.V(2006) Determining the composition of mineralorganic mixes using UV-vis-NIR diffuse reflectance spectroscopy. Geoderma 31 (1-2):70-82. https://doi.org/10.1016/j.geoderma.2006.07.004.

Rui X, Pan Z, Qian W, Xiaomao W, Kaichang Y, Tao X, Xianghua W(2019) Influences of multi influent matrices on the retention of PPCPs by nanofiltration membranes. Separation and Purification Technology 212:299-306. https://doi.org/10.1016/j.seppur.2018.11.040. 
Talbi M.L (2011) Analyse et traitement du signal électrocardiographique (ECG), University of Mentouri of Constantine, Algeria.

Tang CY, Kwon Y-N, Leckie JO (2009) Effect of membrane chemistry and coating layer on physiochemical properties of thin film composite polyamide RO and NF membranes: II. Membrane physiochemical properties and their dependence on polyamide and coating layers. Desalination 242 (1-3):168-182. http://dx.doi.org/10.1016/j.desal.2008.04.004.

Teychene B, Chi F, Chokki J, Darracq G, Baronn J, Joyeux M, Gallard H (2020) Investigation of polar mobile organic compounds (PMOC) removal by reverse osmosis and nanofiltration: rejection mechanism modelling using decision tree. Water Supply 20(3) 975-983. https://doi.org/10.2166/ws.2020.020.

Yangali-Quintanilla V, Kennedy M, Amy G, Kim TU (2008) Modeling of RO/NF membrane rejections of PhACs and organic compounds: A statistical analysis. Drinking Water Engineering and Science 1 (1):7-15. http://dx.doi. 10.5194/dwes-1-7-2008.

Yangali-Quintanilla V, Sadmani A, McConville M, Kennedy M, AmyG A (2010) QSAR model for predicting rejection of emerging contaminants (pharmaceuticals, endocrine disruptors) by nanofiltration membranes. Water Research $44 \quad$ (3): 373-384. http://dx.doi.org/10.1016/j.watres.2009.06.054.

Yangali-Quintanilla V, Verliefde A, Kim TU, Sadmani A, Kennedy M, Amy G (2009) Artificial neural network models based on QSAR for predicting rejection of neutral organic compounds by polyamide nanofiltration and reverse osmosis membranes. Journal of Membrane Science 342 (12):251-262. http://dx.doi.org/10.1016/j.memsci.2009.06.048.

Yang Y.Z, Xiao M, Hong-wei Y, Yue-feng F.X (2018) Effects of organic fouling and cleaning on the retention of pharmaceutically active compounds by ceramic nanofiltration membranes. Journal of Membrane Science 1:734-742. https://doi.org/10.1016/j.memsci.2018.06.047. 
Table 2. Structures of the optimized FNN-MLP models.

\begin{tabular}{|c|c|c|c|c|c|c|}
\hline & \multirow{2}{*}{$\begin{array}{l}\text { Training } \\
\text { Algorithm }\end{array}$} & \multirow{2}{*}{$\begin{array}{l}\text { Input } \\
\text { layer } \\
\text { Neurons } \\
\text { number }\end{array}$} & \multicolumn{2}{|c|}{ Hidden layer } & \multicolumn{2}{|c|}{ Output layer } \\
\hline & & & $\begin{array}{l}\text { Neurons } \\
\text { number }\end{array}$ & $\begin{array}{l}\text { Activation } \\
\text { function }\end{array}$ & $\begin{array}{l}\text { Neurons } \\
\text { number }\end{array}$ & $\begin{array}{l}\text { Activation } \\
\text { function }\end{array}$ \\
\hline $\begin{array}{l}\bar{\Delta} \\
\vec{B} \\
\vec{Z} \\
\vec{Z}\end{array}$ & \multirow{3}{*}{$\begin{array}{l}\text { BFGS } \\
\text { quasi- } \\
\text { Newton } \\
\text { (trainbfg) }\end{array}$} & \multirow{3}{*}{13} & 9 & $\begin{array}{l}\text { Hyperbolic } \\
\text { tangent } \\
\text { sigmoid } \\
\text { (tansig) }\end{array}$ & \multirow{3}{*}{1} & \multirow{3}{*}{ Purelin } \\
\hline 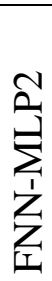 & & & 10 & $\begin{array}{l}\text { Hyperbolic } \\
\text { tangent } \\
\text { sigmoid } \\
\text { (tansig) }\end{array}$ & & \\
\hline $\begin{array}{l}\sum_{i} \\
\sum_{i} \\
\sum_{I}\end{array}$ & & & 15 & $\begin{array}{l}\text { Log sigmoid } \\
(\operatorname{logsig})\end{array}$ & & \\
\hline
\end{tabular}


Table 3. Comparative performance of FNN-RBF models.

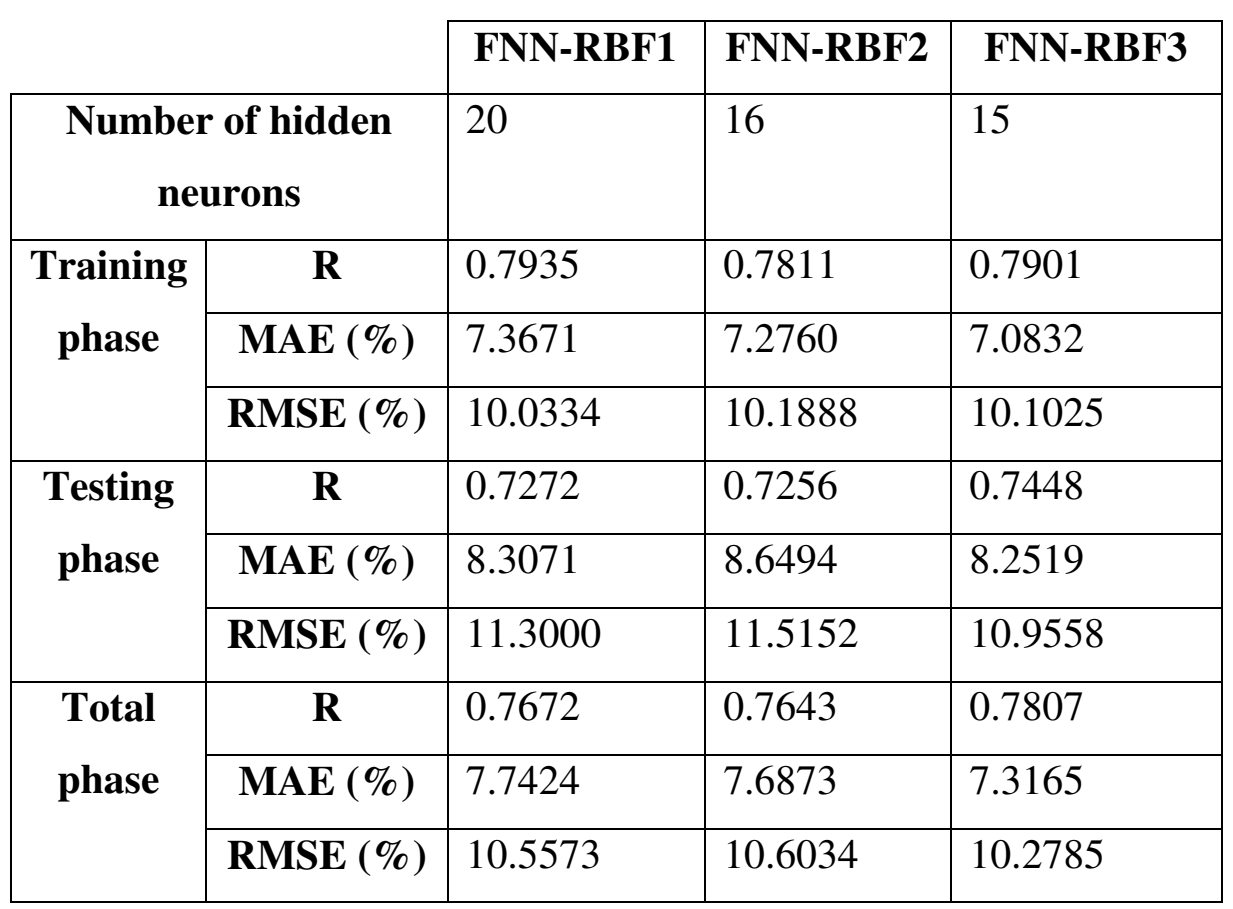


Table 4. Comparative performance of optimal models.

\begin{tabular}{|l|c|c|c|}
\hline & FNN-MLP & FNN-RBF & SVM \\
\hline R & 0.9714 & 0.7807 & 0.9677 \\
\hline MAE & 2.4410 & 7.3165 & 2.9686 \\
\hline MPE & 3.3318 & 19.5531 & 4.1717 \\
\hline RMSE & 3.9139 & 10.2785 & 4.1598 \\
\hline SEP & 4.4784 & 11.7610 & 4.7598 \\
\hline RER & $25.22--05$ & 9.6036 & 23.7295 \\
\hline RPD & 4.2043 & 1.6009 & 3.9558 \\
\hline MSE & 15.3184 & 105.6467 & 17.3039 \\
\hline MRSE & $2.05 \mathrm{E}-05$ & $1.93 \mathrm{E}-04$ & $2.0771 \mathrm{E}-05$ \\
\hline RAE & 0.0045 & 0.0139 & 0.0046 \\
\hline $\mathbf{A}_{\mathbf{f}}$ & 1.0060 & 1.0012 & 1.0055 \\
\hline $\mathbf{B}_{\mathbf{f}}$ & 1.0060 & 1.0012 & 1.0055 \\
\hline RAE & 0.1967 & 0.5895 & 0.2392 \\
\hline NSE & $1.15 \mathrm{E}+25$ & $1.38 \mathrm{E}+24$ & $3.69 \mathrm{E}+24$ \\
\hline
\end{tabular}




\section{Figures}

\section{Fig 1}

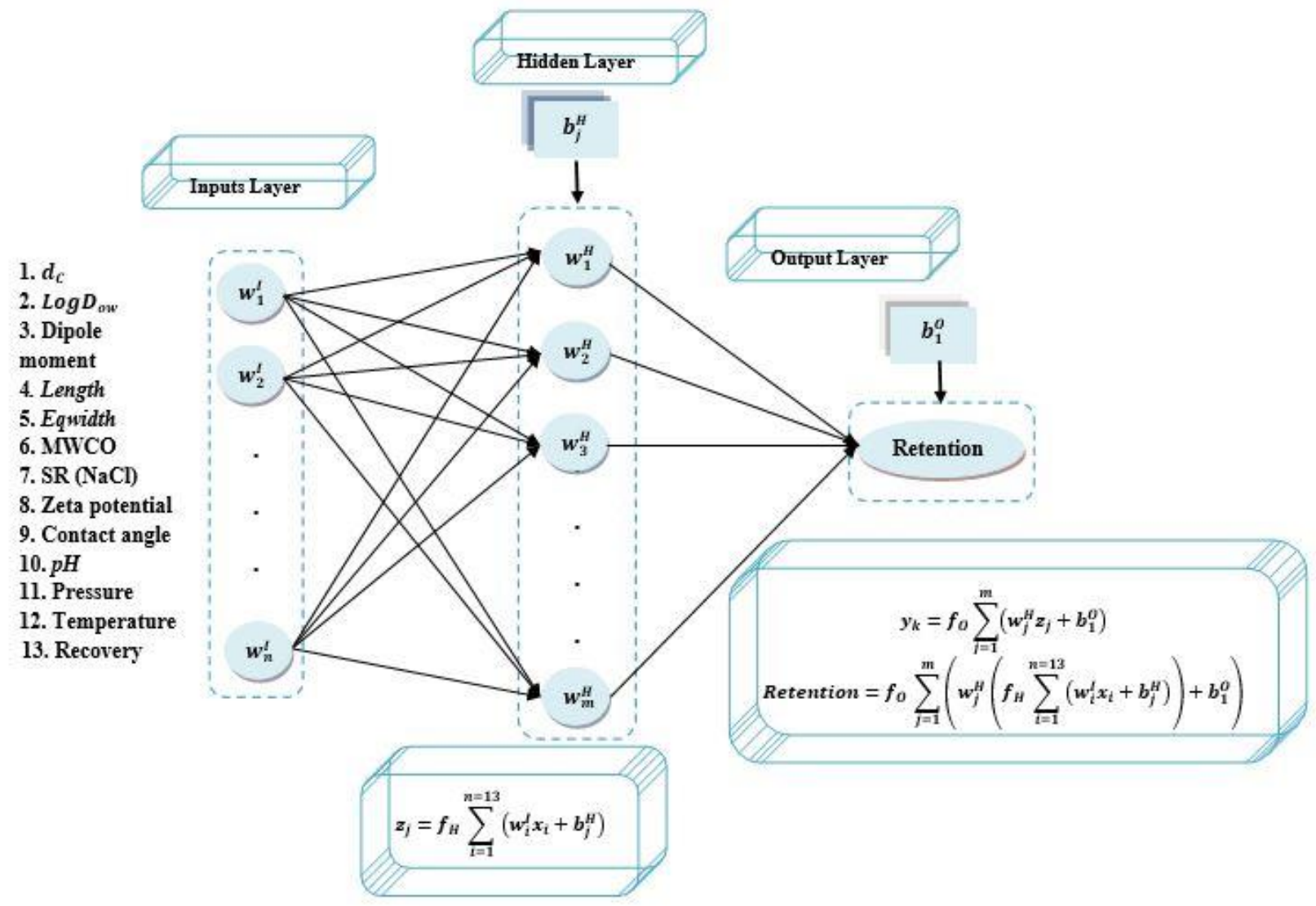


Fig 2

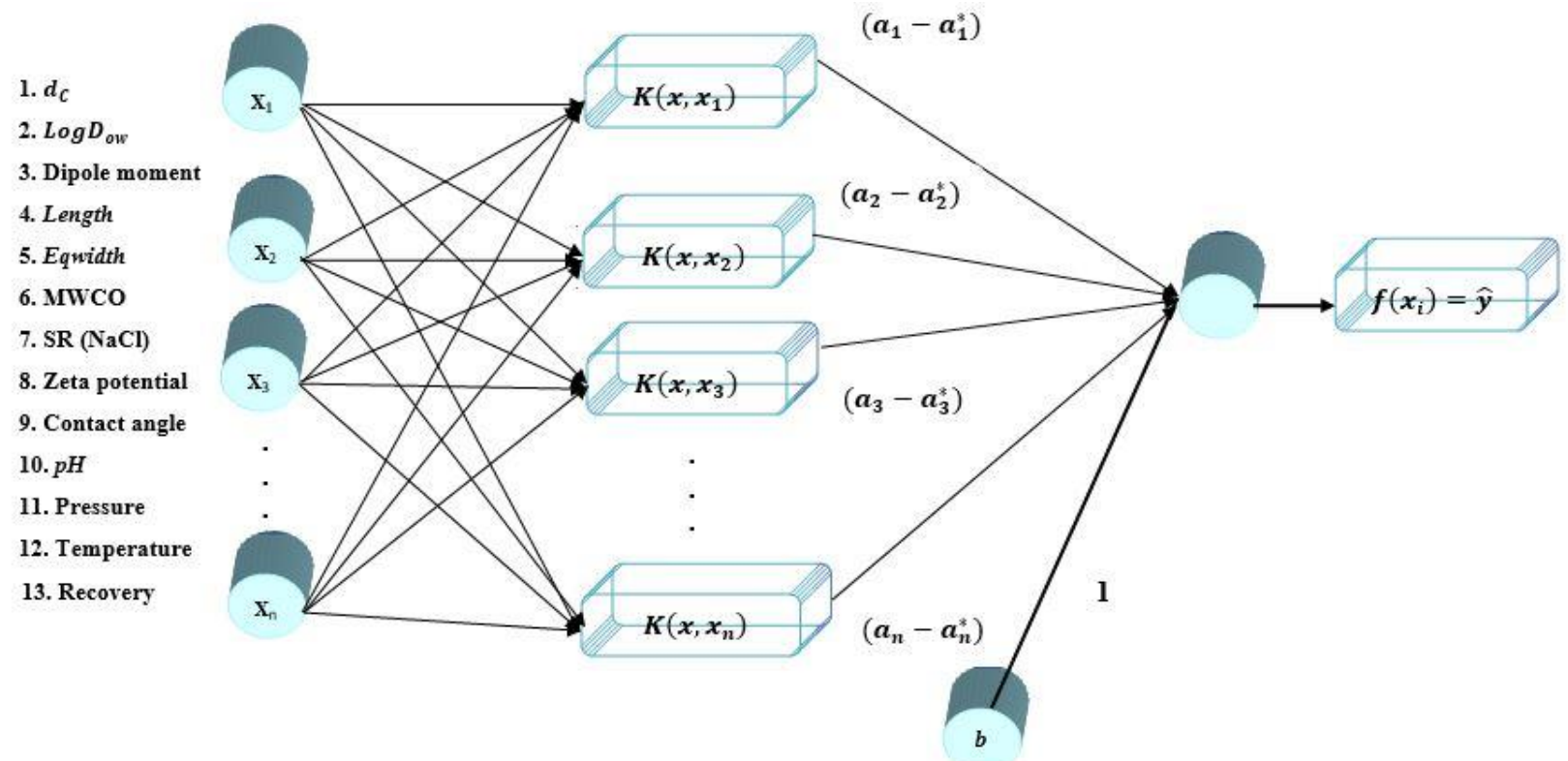




\section{Fig 3}

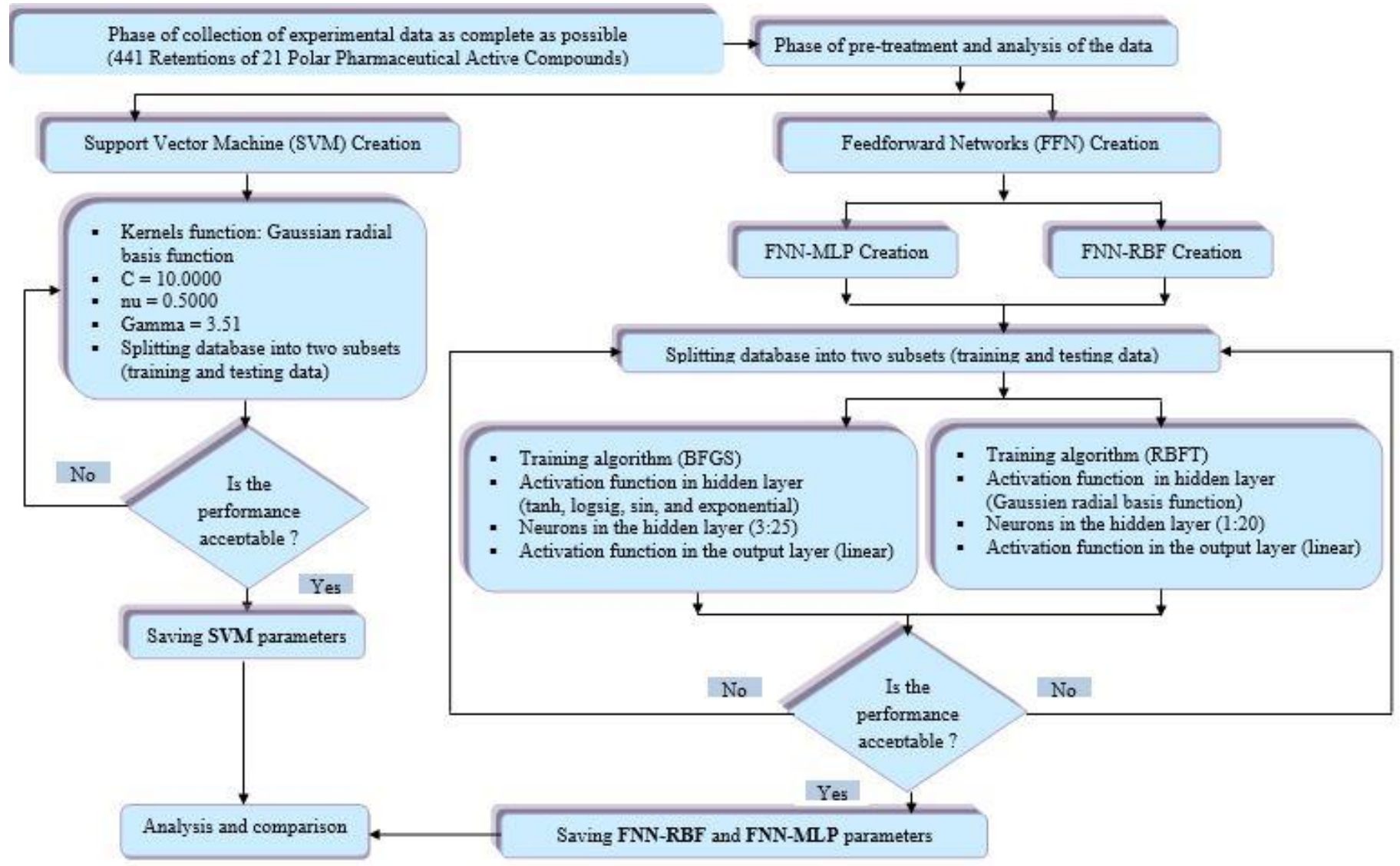


Fig 4

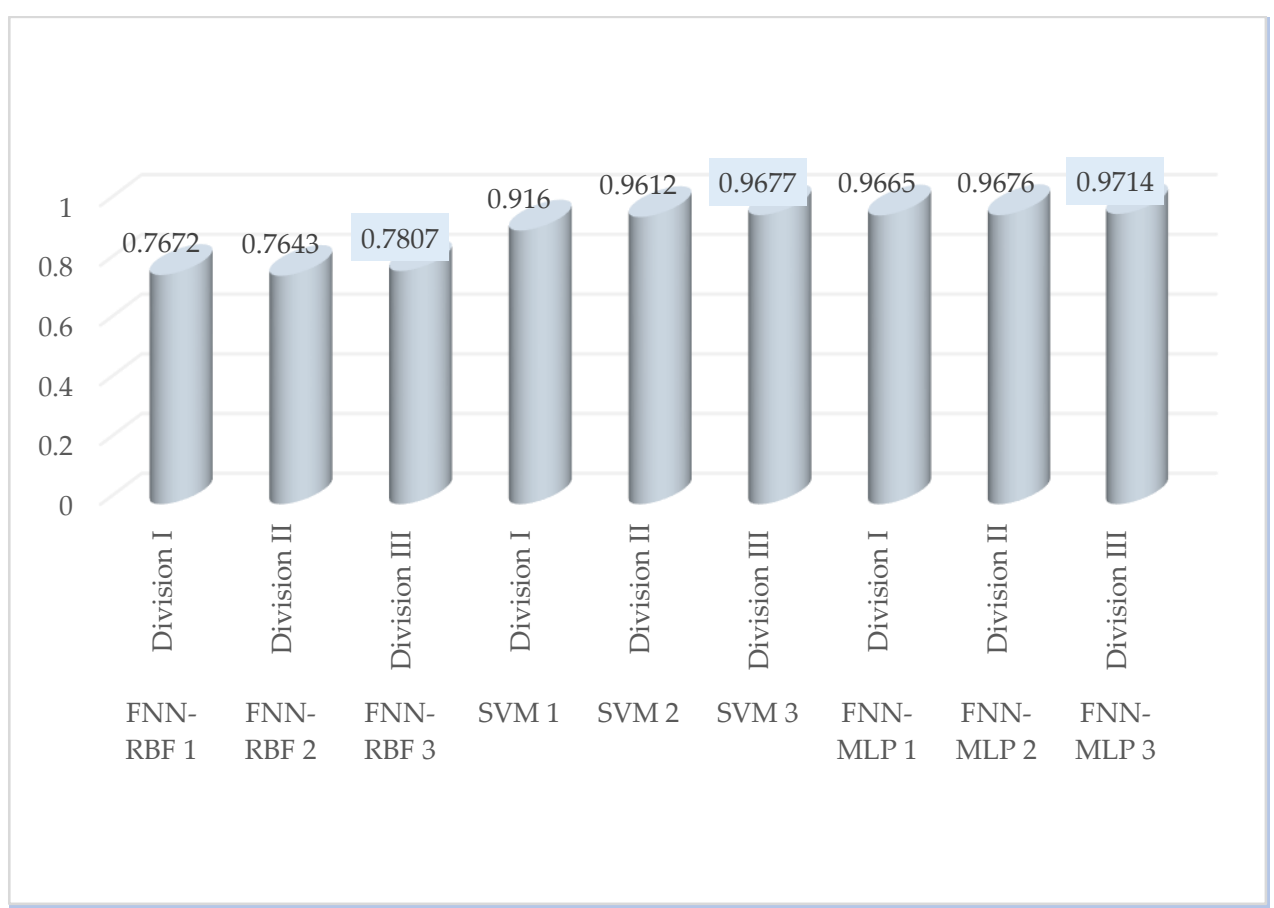


Fig 5

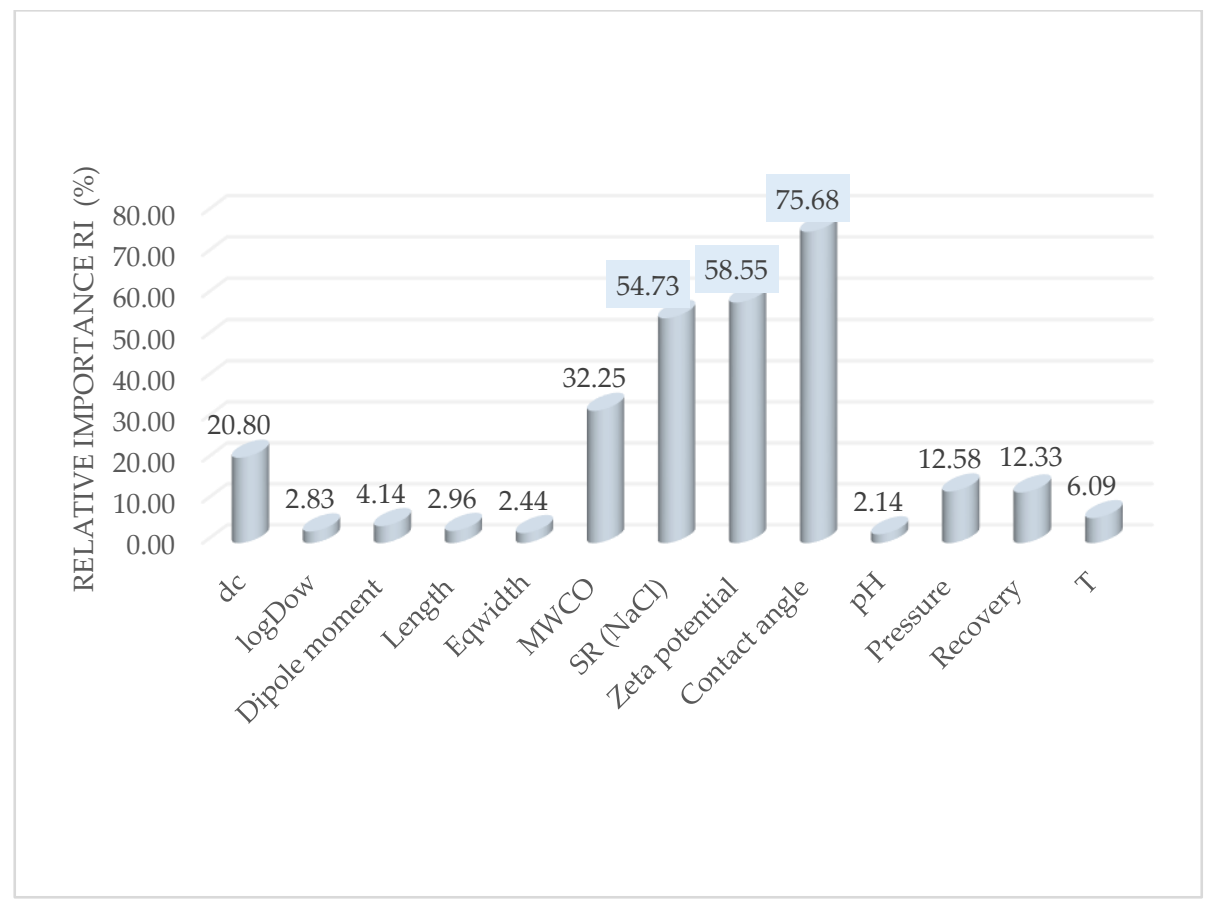


Fig 6 (a)

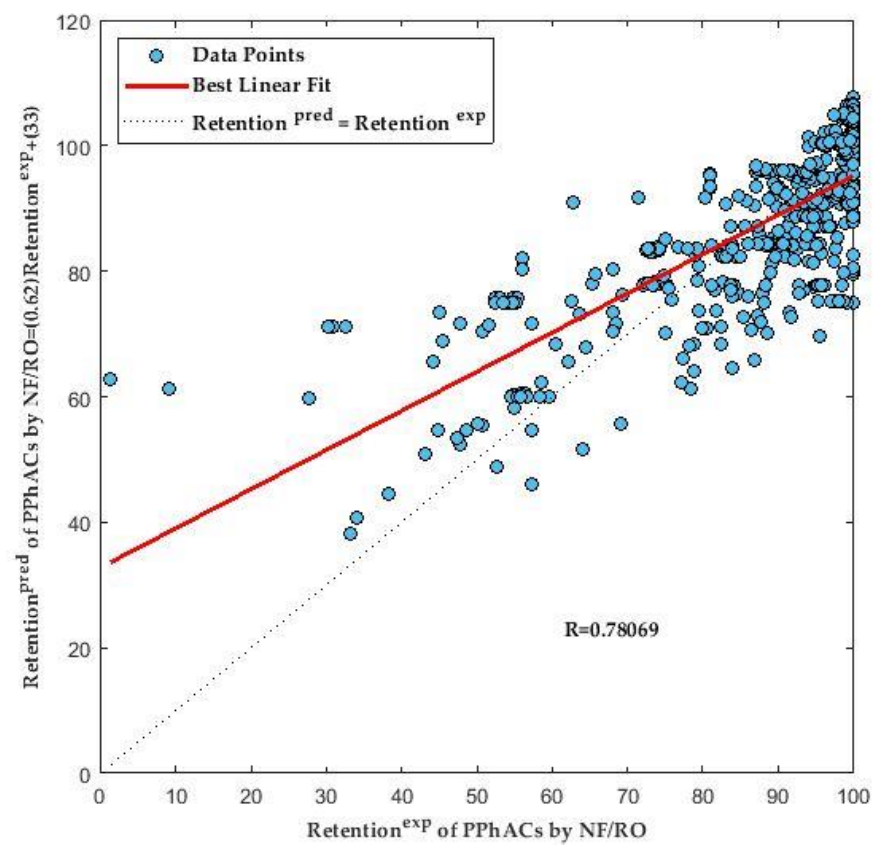


Fig 6(b)

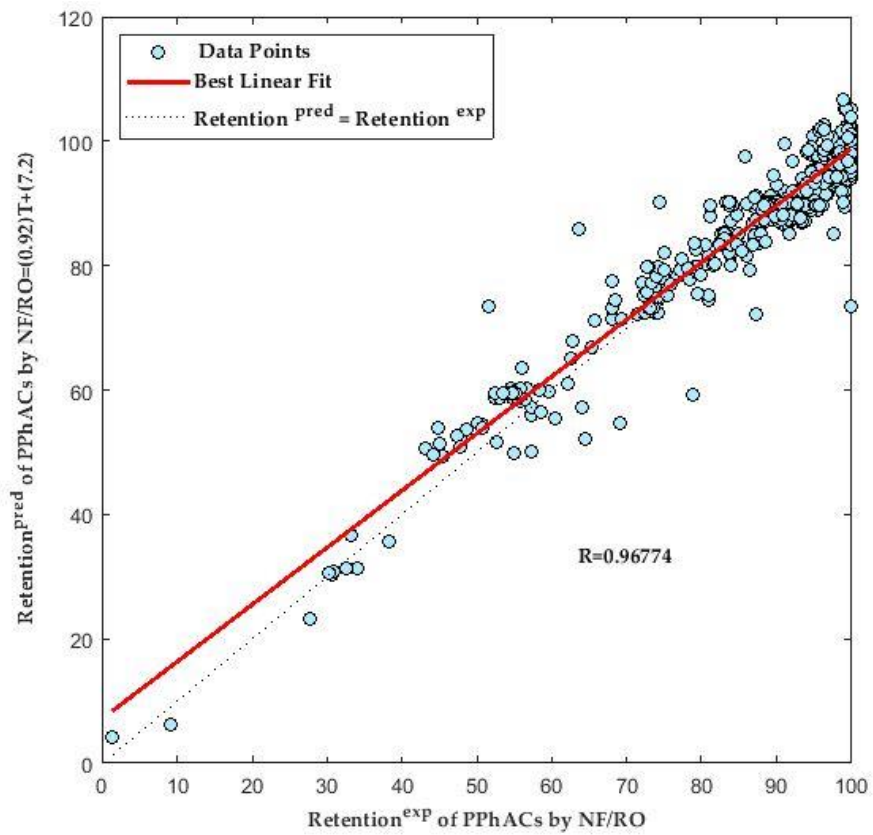


Fig 6 (c)

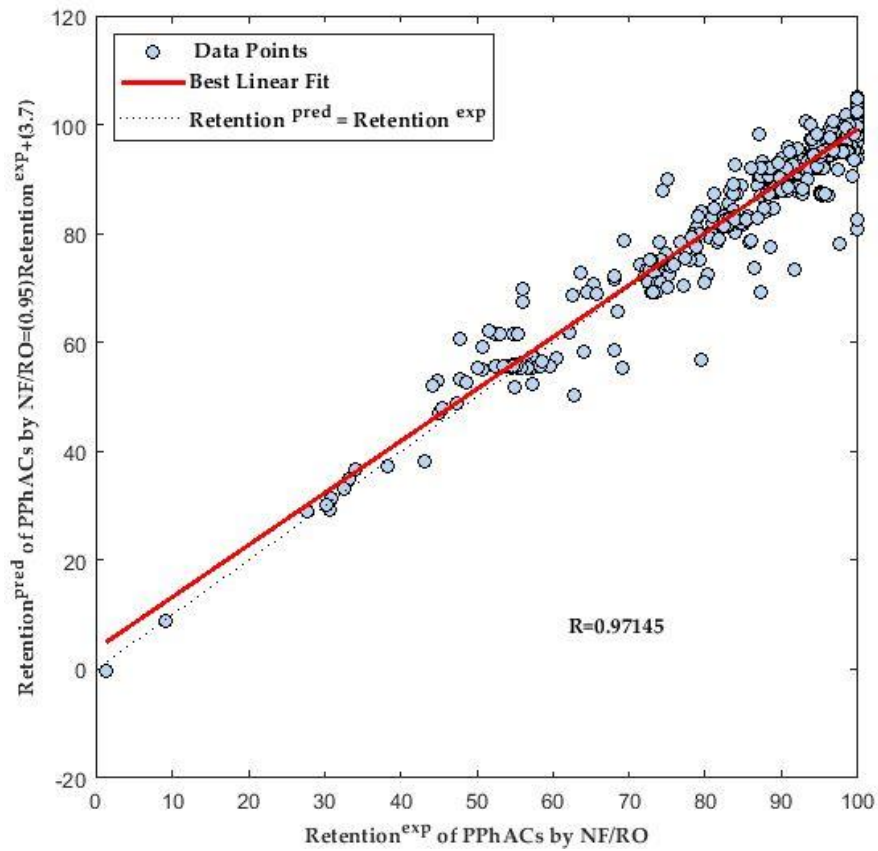


Fig 7 (a)

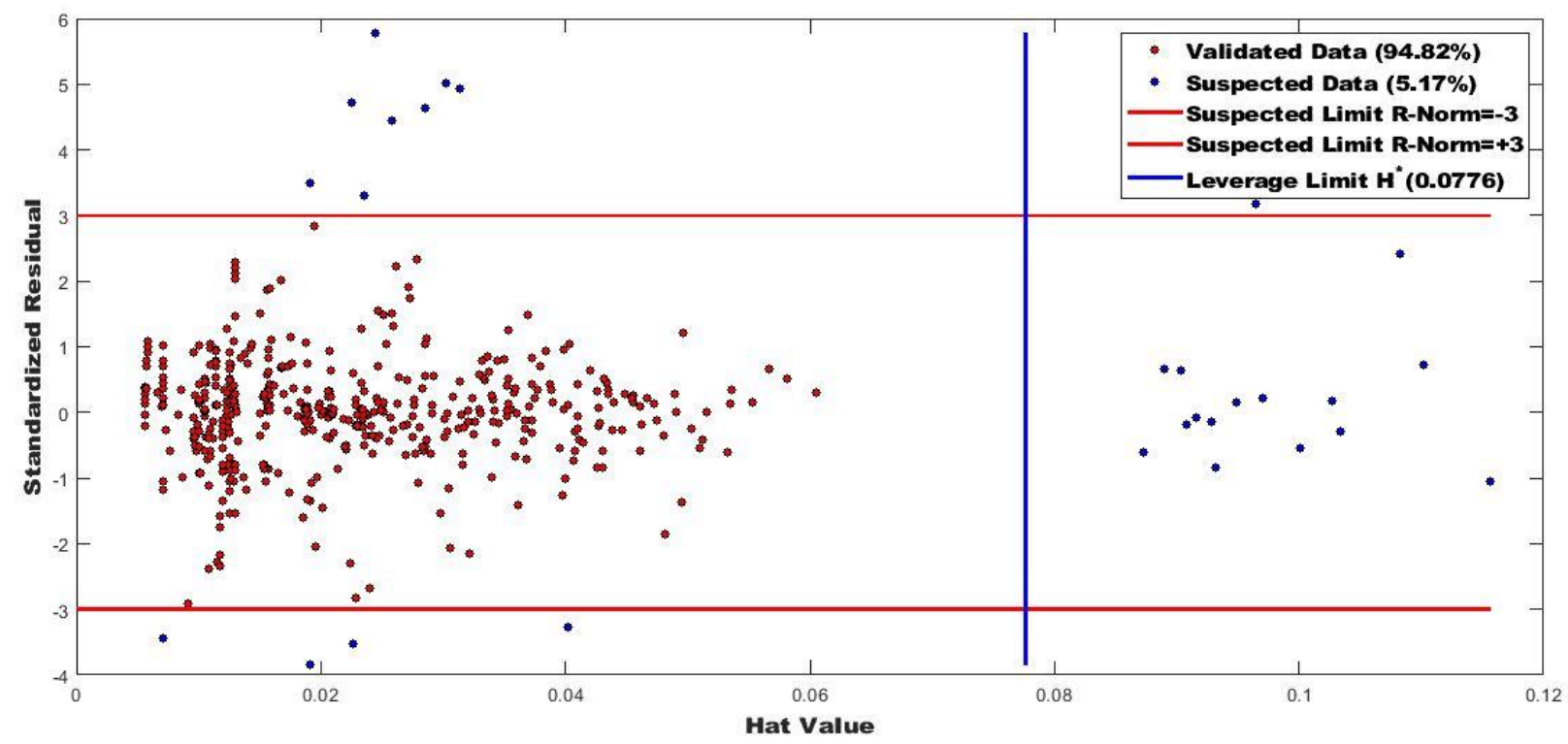


Fig 7 (b)

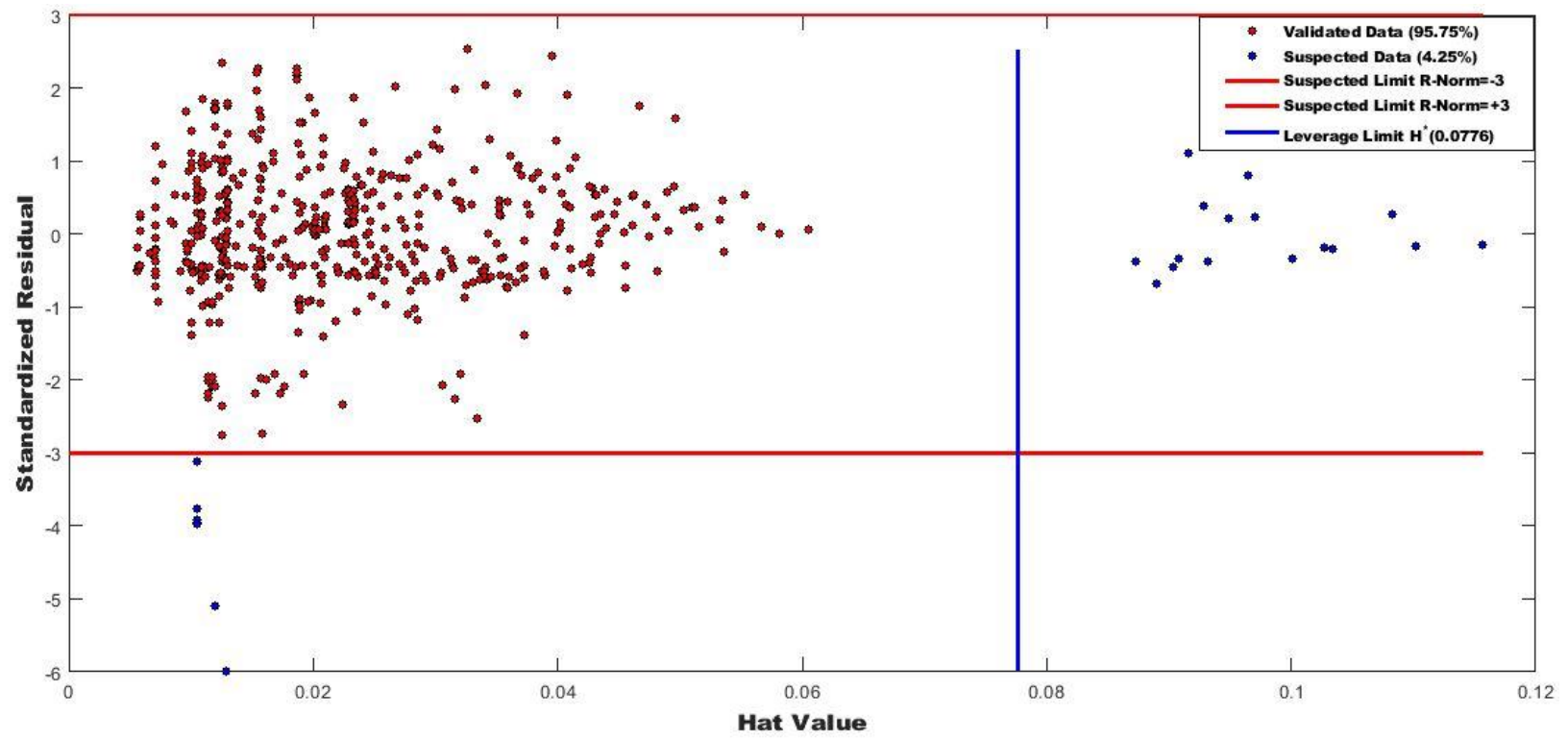


Fig 7 (c)

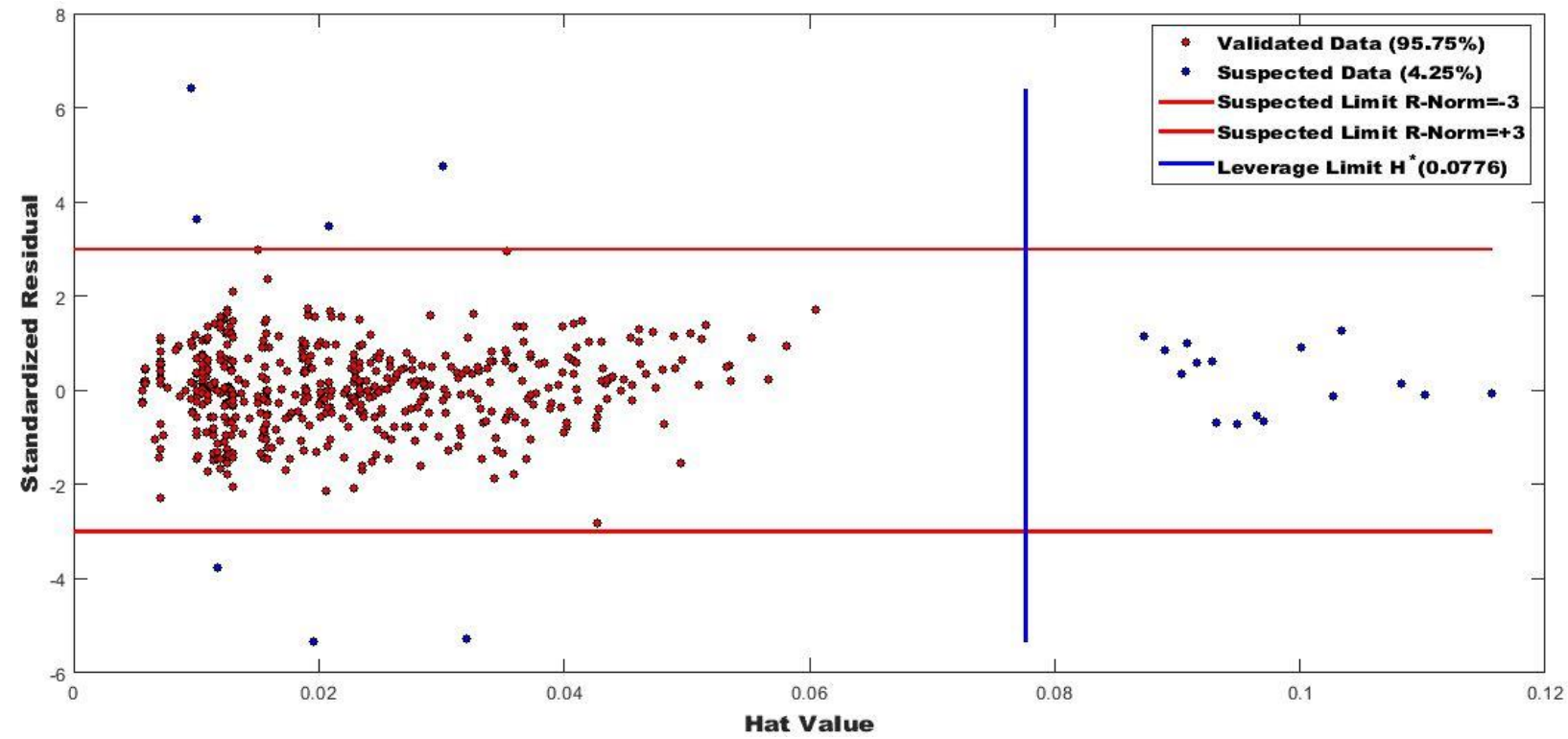




\section{Figures legends}

Fig 1. Structure of feedforward neural networks (FNN).

Fig 2. The sketch map of the support vector machine (SVM) model.

Fig 3. Flow diagram for the feedforward neural networks multi-layer perceptron (FNN-MLP) and feedforward neural networks radial basis function (FNN-RBF), and support vector machine (SVM) development.

Fig 4. Effect of the division of the database in term coefficient correlation (R).

Fig 5. The plot of the relative importance (RI) of the FNN-MLP3 model for modeling the retention of PPhACs by NF/RO membranes.

Fig 6. Predicted vs experimental phase agreement plot: a for the FFN-RBF3, b for the SVM3, and c FFN-MLP3.

Fig 7. William's Diagram for detection of outliers for the optimal models: a for FNN-MLP3, b for FNN-RBF3, and c for SVM. 


\section{Supplementary Files}

This is a list of supplementary files associated with this preprint. Click to download.

- SupplementarydataA.docx 